\title{
Plantas tóxicas para ruminantes e equî́deos no Seridó Ocidental e Oriental do Rio Grande do Norte ${ }^{1}$
}

\author{
Durval M. da Silva ${ }^{2}$, Franklin Riet-Correa ${ }^{3}$, Rosane M.T. Medeiros ${ }^{3}$ e \\ Odaci F. de Oliveira ${ }^{4}$
}

\begin{abstract}
Silva D.M., Riet-Correa F., Medeiros R.M.T. \& Oliveira O.F. 2006. [Toxic plants for livestock in the western and eastern Seridó, state of Rio Grande do Norte, in the Brazilian semiarid.] Plantas tóxicas para ruminantes no Seridó Ocidental e Oriental do Rio Grande do Norte. Pesquisa Veterinária Brasileira 26(4):223-236. Hospital Veterinário, CSTR, Universidade Federal de Campina Grande, Campus de Patos, 58700-000 Patos, PB, Brazil. E-mail: franklin.riet@pesquisador.com.br

To determine the occurrence of plant poisoning in the Western and Eastern Seridó regions of the state of Rio Grande do Norte, 82 persons including farmers, agronomists and veterinarians were interviewed. The two more important toxic plants are Ipomoea asarifolia, which causes nervous signs in sheep, goats and cattle, and Aspidosperma pyrifolium, leading to abortion in goats, sheep and cattle. The abortive properties of this plant had been demonstrated experimentally in goats, but not in sheep and cattle. Some farmers mentioned the poisoning by A. pyrifolium as a cause of nervous signs in equidae and cattle. Poisoning by cyanogenic plants including Manihot spp, Anadenanthera colubrina var. cebil (=Piptadenia macrocarpa), Sorghum bicolor and Sorghum halepense are important in the region. Important is also poisoning by Prosopis juliflora in cattle and with less frequency in goats, poisoning by Crotalaria retusa in horses, sheep and cattle, and by Mascagnia rigida in cattle. Poisoning by Brachiaria decumbens and Enterolobium contortisiliquum is sporadic. Other less important toxic plants in the region are Indigofera suffruticosa, Ipomoea carnea, and Ricinus communis. Some farmers reported poisoning by Marsdenia sp affecting sheep and cattle, and also a group of swine fed with the roots of the plant; the leaves and the roots are experimentally toxic to ruminants causing nervous signs, without histologic lesions. Another poisoning demonstrated experimentally is caused by Tephrosia cinerea and results in ascitis with hepatic fibrosis in sheep. Six farmers reported poisoning by Nerium oleander, always in cattle that had access to the shrub after been cut, mixed or not with other plants. Farmers mentioned also poisoning by other plants with unknown toxicity, including Paullinia sp, Passiflora sp, Dalechampia sp, Portulaca oleracea, Luffa acutangula, Cereus sp, Leersia hexandra, and Stemodia maritima. Echinochloa polystachya and Pennisetum purpureum, which cause nitrite poisoning were mentioned by some farmers as cause of cattle mortalities. One farmer mentioned an outbreak of poisoning in cattle and goats by Dieffenbachia picta which had been cut and left to the animals.
\end{abstract}

INDEX TERMS: Toxic plants, ruminants, semiarid region, Rio Grande do Norte.

\footnotetext{
${ }^{1}$ Recebido em 12 de maio de 2006.

Aceito para publicação em 5 de junho de 2006.

Parte da tese do primeiro autor no Programa de Mestrado em Medicina Veterinária de Pequenos Ruminantes, CSTR, Universidade Federal de Campina Grande, Paraíba.

2 Pósgraduando, Rua Joel Damasceno 759, Caicó, RN 59300-000. E-mail: durvalmorais@terra.com.br

${ }^{3}$ Hospital Veterinário, CSTR, Universidade Federal de Campina Grande, Campus de Patos, 58700-000 Patos, PB. *Autor para correspondência: franklin.riet@pesquisador.cnpq.br

${ }^{4}$ Escola Superior de Agricultura de Mossoró, RN 59625-900.
}

RESUMO.- Para determinar a ocorrência de diferentes intoxicações por plantas na região do Seridó Ocidental e Oriental do Rio Grande do Norte foram entrevistadas 82 pessoas, entre produtores e técnicos em 17 municípios. De acordo com esse inquérito as duas intoxicações mais importantes são as por Ipomoea asarifolia, que causa sinais nervosos em ovinos, caprinos e bovinos, e por Aspidosperma pyrifolium que, segundo os entrevistados, causaria abortos em caprinos, ovinos e bovinos. $\mathrm{O}$ efeito abortivo desta última planta foi comprovado em caprinos, mas não em bovinos e ovinos. Alguns entrevistados mencionaram, também, a intoxicação por $A$. pyrifolium como causa de sinais 
nervosos em bovinos e equiídeos, o que ainda não foi comprovado. Intoxicações por plantas cianogênicas, incluindo Manihot spp, Anadenanthera colubrina var. cebil (=Piptadenia macrocarpa), Sorghum bicolor e Sorghum halepense são importantes na região. São importantes, também, as intoxicações por Prosopis juliflora em bovinos e, com menor freqüência, em caprinos, por Crotalaria retusa em eqüinos, ovinos e bovinos e por Mascagnia rigida em bovinos. As intoxicações por Brachiaria decumbens e Enterolobium contortisiliquum ocorrem esporadicamente. Outras intoxicações menos importantes são as causadas por Indigofera suffruticosa, Ipomoea carnea e Ricinus communis. Diversos produtores descreveram a intoxicação por Marsdenia sp afetando ovinos e bovinos, além de um surto em suínos que foram alimentados com as raízes da planta. Foi demonstrado que tanto as raízes da planta quanto as folhas são tóxicas para ruminantes, causando sinais nervosos, mas sem lesões histológicas. Outra intoxicação relatada pelos produtores e comprovada experimentalmente foi a causada por Tephrosia cinerea em ovinos, que causa um quadro clínico de ascite, com lesões de fibrose hepática. Seis produtores descreveram a intoxicação por Nerium oleander, sempre em bovinos que tiveram acesso à planta após esta ter sido cortada e misturada ou não com outras plantas. Os produtores mencionaram, também, as intoxicações por diversas plantas cuja toxicidade em forma espontânea não está comprovada, incluindo Paullinia sp, Passiflora sp, Dalechampia sp, Portulaca oleracea, Luffa acutangula, Cereus sp, Leersia hexandra e Stemodia maritima. Echinochloa polystachya e Pennisetum purpureum, que podem causar intoxicação por nitratos e nitritos, foram mencionadas por alguns produtores com causa de morte em bovinos. Um produtor descreveu um surto de intoxicação em bovinos e caprinos por Dieffenbachia picta que tinha sido cortada e colocada ao alcance dos animais.

TERMOS DE INDEXAÇÃO: Plantas tóxicas, ruminantes, semi-árido.

\section{INTRODUÇÃO}

No Brasil são conhecidas 111 plantas tóxicas (Riet-Correa et al. 2006b). Destas, as mais importantes são Palicourea marcgravii, em todo o País exceto a região sul, Senecio spp e Ateleia glazioviana na região sul, e Cestrum laevigatum na região sudeste, todas para bovinos, e Brachiaria spp em todo o País principalmente no Centro Oeste, para todas as espécies. Na região Nordeste são conhecidas pelo menos 38 plantas tóxicas, sendo as mais importantes Mascagnia rígida, Thiloa glaucocarpa, para bovinos, e Mimosa tenuiflora, principalmente para caprinos e ovinos (Tokarnia et al. 2000, Riet-Correa et al. 2006ab). O estudo sistemático das plantas tóxicas, em regiões com poucas pesquisas sobre as mesmas, aumenta consideravelmente o número de espécies tóxicas conhecidas. Um exemplo disso é o Estado da Paraíba, onde até o ano 2000 eram conhecidas 8 plantas tóxicas e, após a criação de um grupo de pesquisa em plantas tóxicas esse número aumentou para 21 plantas tóxicas (Riet-Correa et al. 2006a).

Considerando-se que não há informações sobre as plantas tóxicas do Rio Grande do Norte e sua importância econômica, este trabalho teve como objetivo determinar as plantas tóxicas das microrregiões do Seridó Oriental e Ocidental desse Estado (Fig.1), assim como a sua distribuição geográfica na região. Para

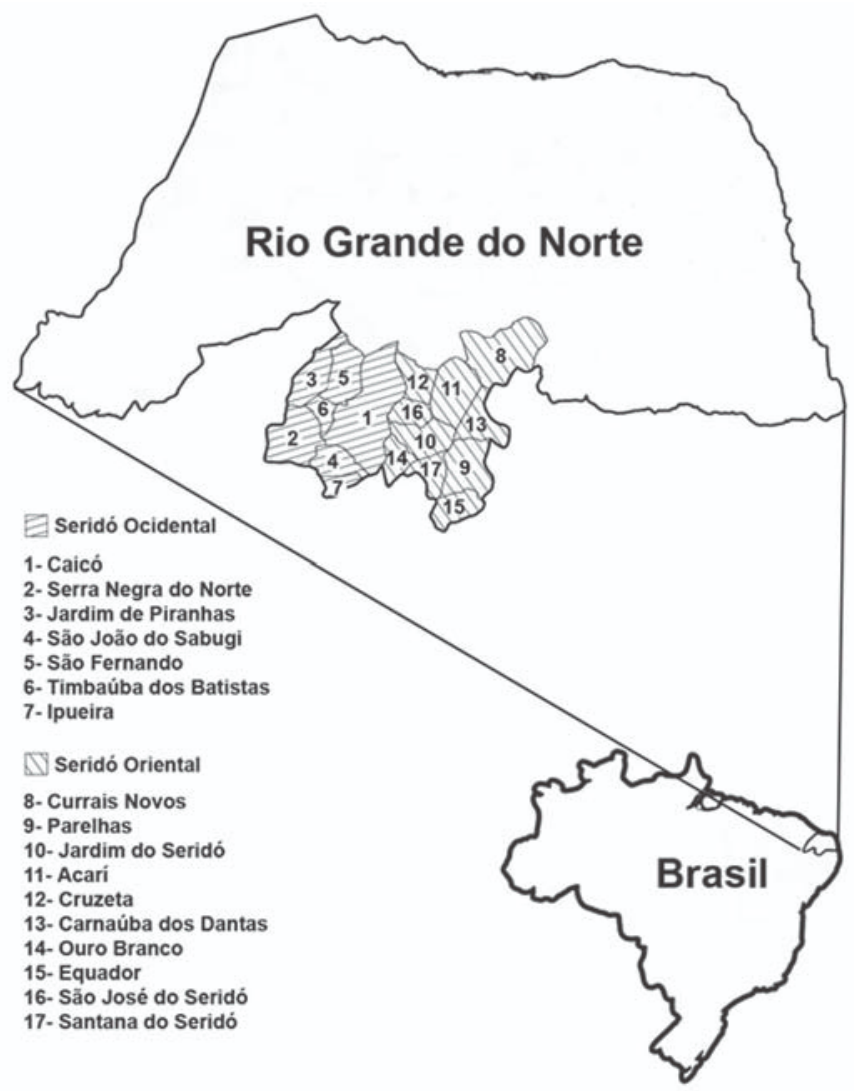

Fig.1. Mapa do Rio Grande do Norte mostrando as regiões do Seridó Oriental e Ocidental, onde foi realizado o levantamento sobre plantas tóxicas para ruminantes.

isso, foram entrevistados produtores, médicos veterinários e agrônomos que atuam na região. O desenvolvimento deste trabalho objetivou, também, desenvolver uma metodologia que permita ser aplicada em outras regiões do País onde não há suficiente informação sobre plantas tóxicas e, além disso, estabelecer linhas de pesquisa para comprovar a toxicidade de plantas suspeitas de serem tóxicas.

\section{MATERIAL E MÉTODOS}

O trabalho foi realizado nas microrregiões do Seridó Oriental e Seridó Ocidental do Rio Grande do Norte, na qual se situam 17 municípios com população de 208.266 habitantes, ocupando uma área de 6.970,6 $\mathrm{km}^{2}$ (IDEMA 2002). A região está localizada no Semi-Árido. A paisagem do Seridó caracteriza-se como um solo raso e pedregoso do tipo brono não-cálcico de pouca profundidade e elevada suscetibilidade à erosão; possuindo uma vegetação baixa com cactos espinhentos e agressivos, arbustos espaçados e capins de permeio com manchas desnudas. $\mathrm{O}$ clima é quente e seco com temperaturas variando entre as médias mínimas e máximas de 22 a $33^{\circ} \mathrm{C}$, respectivamente; possuindo duas estações irregulares, uma de chuvas (janeiro-maio) e a outra de estiagem (junho-dezembro); com pluviosidade média anual de $497 \mathrm{~mm}^{3}$. Na região ocorrem secas, de abrangência total ou parcial e duração anual ou plurianual. A insolação média é de 2.988 horas de luz solar por ano. Tradicionalmente, é uma região de criação de gado desde o início de sua exploração com rebanhos vindos da região do Piauí (Duque 1964). Na região há um rebanho de 140.567 bovinos, 67.363 ovinos, 16.525 caprinos e 12.212 equiídeos (IDEMA 2002). 
Para determinar a ocorrência das intoxicações por plantas na região do Seridó Oriental e Ocidental do Rio Grande do Norte foram entrevistados 68 produtores, sendo 4 por município, de um total de 17 municípios. Foram entrevistados, também, 4 engenheiros agrônomos e 10 médicos veterinários que exercem suas atividades na região. Para as entrevistas foram utilizados 3 formulários (Anexos 1, 2 e 3), sendo que os Formulários 1 e 2 foram aplicados a todos os entrevistados e o Formulário 3 somente àqueles que se mostraram interessados em descrever surtos de intoxicações que haviam presenciado. No Formulário 1 perguntava-se sobre as plantas conhecidas como tóxicas na região nordeste. As perguntas eram formuladas mencionando o (s) nome (s) comum (ns) da planta e, se houvessem dúvidas, era mostrada a fotografia da mesma. No Formulário 3, se questionava sobre as características das intoxicações observadas pelos entrevistados e no Formulário 2, sobre outras plantas conhecidas como tóxicas pelos entrevistados que não foram incluídas no Formulário 1.

As plantas relatadas pelos criadores como causadoras de intoxicações que não estavam no Formulário 1 foram coletadas e identificadas botanicamente por espécie ou por gênero.

\section{Formulário 1. Plantas conhecidas como tóxicas na região Nordeste}

\begin{tabular}{|c|c|c|c|c|}
\hline \multicolumn{5}{|c|}{ 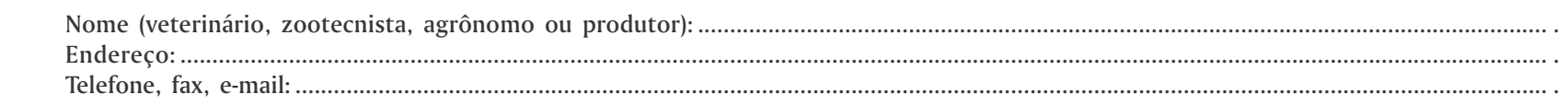 } \\
\hline Planta tóxica & $\begin{array}{l}\text { Existe a } \\
\text { planta } \\
\text { na região? } \\
\text { Sim / Não }\end{array}$ & $\begin{array}{l}\text { Tem visto } \\
\text { caso de } \\
\text { intoxicação? } \\
\text { Sim / Não }\end{array}$ & $\begin{array}{l}\text { Sabe ocor- } \\
\text { rência da } \\
\text { intoxicação } \\
\text { em outras } \\
\text { regiões? Quais? }\end{array}$ & $\begin{array}{l}\text { Quantos surtos } \\
\text { ocorreram em } \\
2004 \text { na região? }\end{array}$ \\
\hline \multicolumn{5}{|l|}{ Aspidosperma pyrifolium (pereiro) } \\
\hline \multicolumn{5}{|l|}{ Brachiaria decumbens (capim-braquiária) } \\
\hline \multicolumn{5}{|l|}{ Crotalaria retusa (chocalho-de-cascavel, gergelin-bravo) } \\
\hline \multicolumn{5}{|l|}{ Enterolobium contortisiliquum (tim-baúba, tamboril)** } \\
\hline \multicolumn{5}{|l|}{ Enterolobium gummiferum (orelha-de-onça, tamboril) ${ }^{* * * *}$} \\
\hline \multicolumn{5}{|l|}{ Indigofera suffruticosa (anil) } \\
\hline \multicolumn{5}{|l|}{ Ipomoea asarifolia (salsa) } \\
\hline \multicolumn{5}{|l|}{ Ipomoea carnea (canudo) } \\
\hline \multicolumn{5}{|l|}{ Ipomoea riedelli (anicão) } \\
\hline \multicolumn{5}{|l|}{ Lantana camara (chumbinho, cambará) } \\
\hline \multicolumn{5}{|l|}{ Manihot spp (maniçoba) } \\
\hline \multicolumn{5}{|l|}{ Mascagnia rigida (tingüí) } \\
\hline \multicolumn{5}{|l|}{ Nerium oleander (espirradeira) } \\
\hline \multicolumn{5}{|l|}{ Piptadenia macrocarpa (angico) } \\
\hline \multicolumn{5}{|l|}{ Plumbago scandens (louco) } \\
\hline \multicolumn{5}{|l|}{ Prosopis juliflora (algaroba) } \\
\hline \multicolumn{5}{|l|}{ Ricinus communis (mamona, carrapateira), sementes } \\
\hline \multicolumn{5}{|l|}{ Ricinus communis (mamona, carrapateira), folhas } \\
\hline \multicolumn{5}{|l|}{ Sorghun vulgare (sorgo) } \\
\hline \multicolumn{5}{|l|}{ Stryphnodendron coriaceum (barbatimão do Nordeste) } \\
\hline Thiloa glaucocarpa (sipaúba, vaqueta) & & & & \\
\hline
\end{tabular}

* Frutos pretos, *** frutos marrons.

Formulário 2. Outras plantas mencionadas pelos produtores como tóxicas e que não foram incluídas no Formulário 1

\begin{tabular}{|l|l|l|}
\hline Planta (nome comum e nome científico) & Quantos surtos ocorreram em 2004 na região? & Principais sinais clínicos e patologia \\
\hline & & \\
\hline & & \\
\hline & & \\
\hline
\end{tabular}


Formulário 3. Surtos de intoxicações por plantas relatado pelos entrevistados

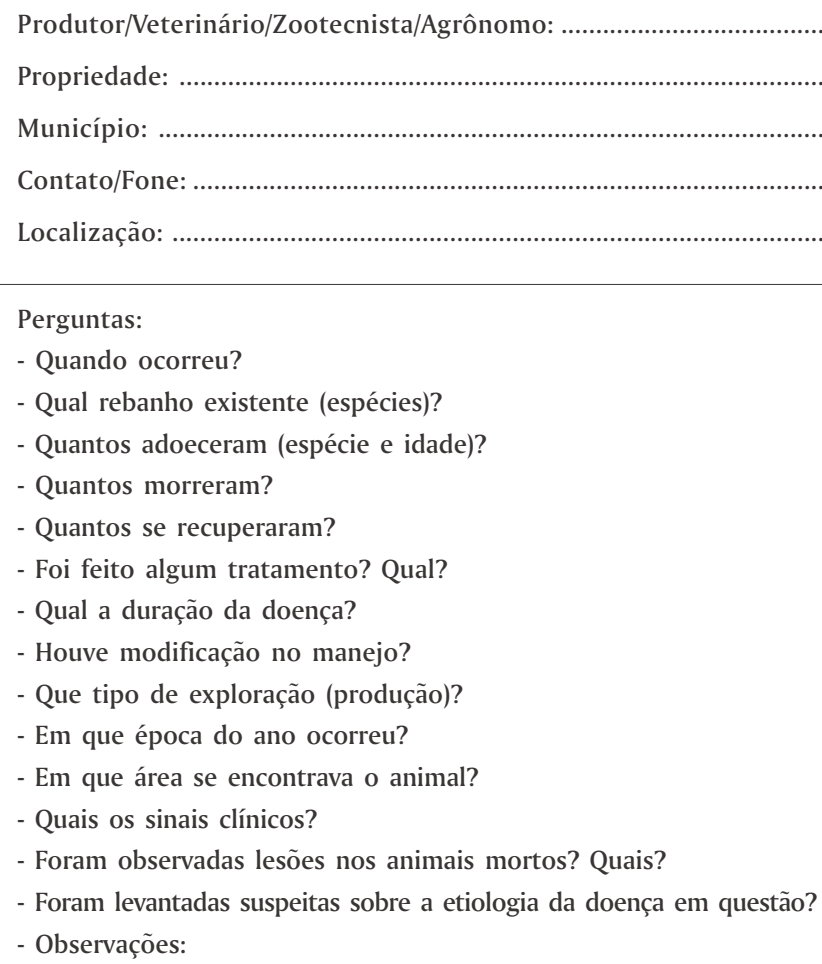

Data

\section{RESULTADOS}

Ocorrência e epidemiologia de intoxicações por plantas já conhecidas como tóxicas na região Nordeste (Formulários 1 e 2)

Os dados obtidos mediante a aplicação do Formulário 1, aplicado a 82 entrevistados são apresentados no Quadro 1. Alguns comentários ou dados mencionados por 62 desses entrevistados no Formulário 3, em relação a cada intoxicação, são mencionados a seguir.

Aspidosperma pyrifolium (pereiro). Sessenta entrevistados relataram a ocorrência de abortos ou nascimento de animais débeis que morrem após o parto. Dois mencionaram que os abortos ocorrem em bovinos, 2 em caprinos, 16 em caprinos e ovinos e 4 em bovinos, caprinos e ovinos. Os demais não especificaram a espécie na qual ocorrem os abortos. Nove entrevistados relataram, também, a ocorrência de intoxicações com sinais nervosos caracterizados por rigidez dos membros posteriores, com dificuldade de locomoção, em 6 surtos envolvendo bovinos, em 2 afetando muares e em 1 afetando eqüinos. A época de maior ocorrência de ambas as formas de intoxicação é na caída das folhas, no início do período de estiagem.

Brachiaria decumbens (capim-braquiária). Um entrevistado tinha presenciado casos de intoxicação em ovinos, que fo- ram transladados, no período de estiagem, para uma área ao lado da barragem do Açu onde tinha exclusivamente Brachiaria decumbens. De um grupo de 200 ovinos de diversas idades adoeceram e morreram aproximadamente 50 , com sinais característicos de fotossensibilização hepatogênica. Um entrevistado relatou a ocorrência da intoxicação em bezerros, um em ovinos, um em caprinos, e dois em bezerros, em outro município não incluído na área estudada (Serra de Santana-RN).

Crotalaria retusa (chocalho-de-cascavel, gergelin-bravo). Três entrevistados relataram casos de intoxicação em bovinos, 5 em cavalos, 3 em ovinos, 3 em caprinos e 1 em emas. 0 entrevistado que observou a intoxicação em emas relatou que, dos 30 bovinos, 15 ovinos, 10 eqüinos e 10 emas do seu rebanho, adoeceram 6 eqüinos e 3 emas. A doença em eqüinos foi diagnosticada no Centro de Saúde e Tecnologia Rural da UFCG, em Patos, as emas foram encontradas mortas e nos eqüinos a duração do quadro clínico foi de aproximadamente 90 dias, sem responder a qualquer tratamento. A intoxicação ocorreu no período de estiagem em um baixio com aproximadamente $50 \%$ da área ocupada pela planta. Nas emas foram encontradas sementes da planta no inglúvio.

Enterolobium contortisiliquum (timbaúba). Cinco entrevistados relatam surtos em bovinos. Em todos os casos foi observada diarréia, sendo que em um caso uma novilha abortou e em outro uma vaca mostrou fotossensibilização.

Indigofera suffruticosa (anil). Três entrevistados relataram a ocorrência de hemoglobinúria (mencionada como urina com sangue) em bovinos.

Ipomoea asarifolia (salsa). Vinte e três produtores relataram a intoxicação em bovinos, 4 em ovinos, principalmente cordeiros, 3 em bovinos e ovinos, e 2 em caprinos. A intoxicação ocorre principalmente na época seca, quando não há mais disponibilidade de forragem, exceto a salsa, que geralmente está verde. Um entrevistado relatou a intoxicação em 2 bezerros lactentes. Em geral, os entrevistados mencionam que os animais se recuperam após serem retirados das áreas com salsa, no entanto, numerosos produtores mencionam a impossibilidade de dispor de pastagens sem salsa, o que causa alta mortalidade. No ano de 2004, um entrevistado relatou que em um rebanho de 70 ovinos, adoeceram 25 cordeiros, dos quais 20 morreram e 5 se recuperaram após terem sido retirados do local e suplementados com ração. Outro relatou a intoxicação em um período de estiagem prolongado, quando de 80 ovinos e 300 bovinos de varias categorias se intoxicaram 50 ovinos e 60 bovinos; desses morreram 30 ovinos (principalmente cordeiros) e 40 bovinos (garrotes e vacas), sendo grande parte desses animais oriundos de outras propriedades, porém alguns animais afetados já se encontravam na propriedade há muito tempo. A intoxicação foi controlada retirando o rebanho da área e administrando silagem e ração. O produtor utilizou herbicida (Tordon $®$ ) para combater a salsa, porém sem sucesso, já que a planta rebrotou no ano seguinte. Outro criador relatou a intoxicação em um rebanho de 600 ovinos, dos quais adoeceram 200 e morreram 170, principalmente cordeiros e marrãs. Outro surto de intoxicação ocorreu numa propriedade com 80 bovinos e 40 ovinos de várias categorias, onde adoeceram 15 bovinos e 10 cordeiros, morrendo 5 cordeiros e nenhum bovino. Os bovinos se recupera- 


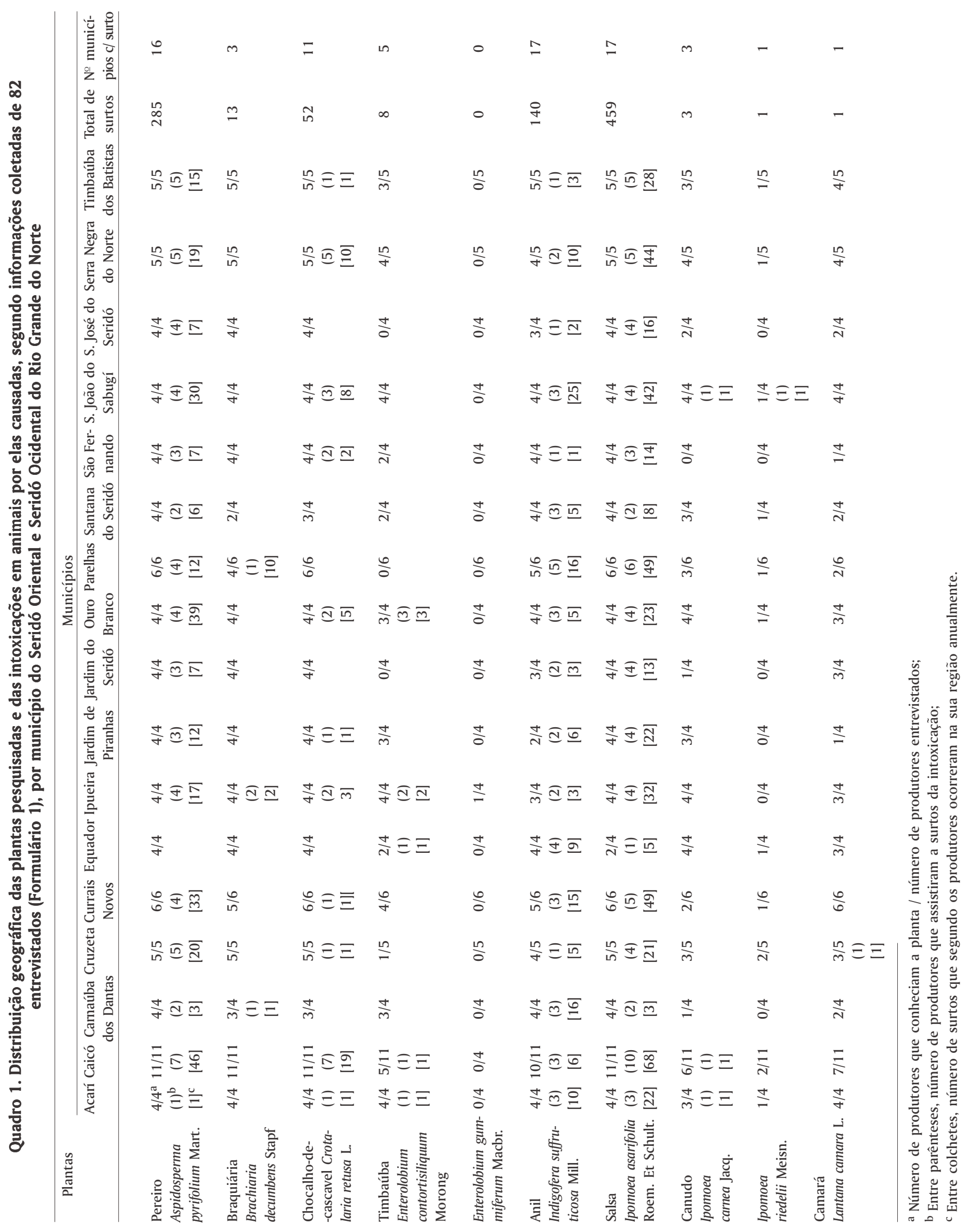




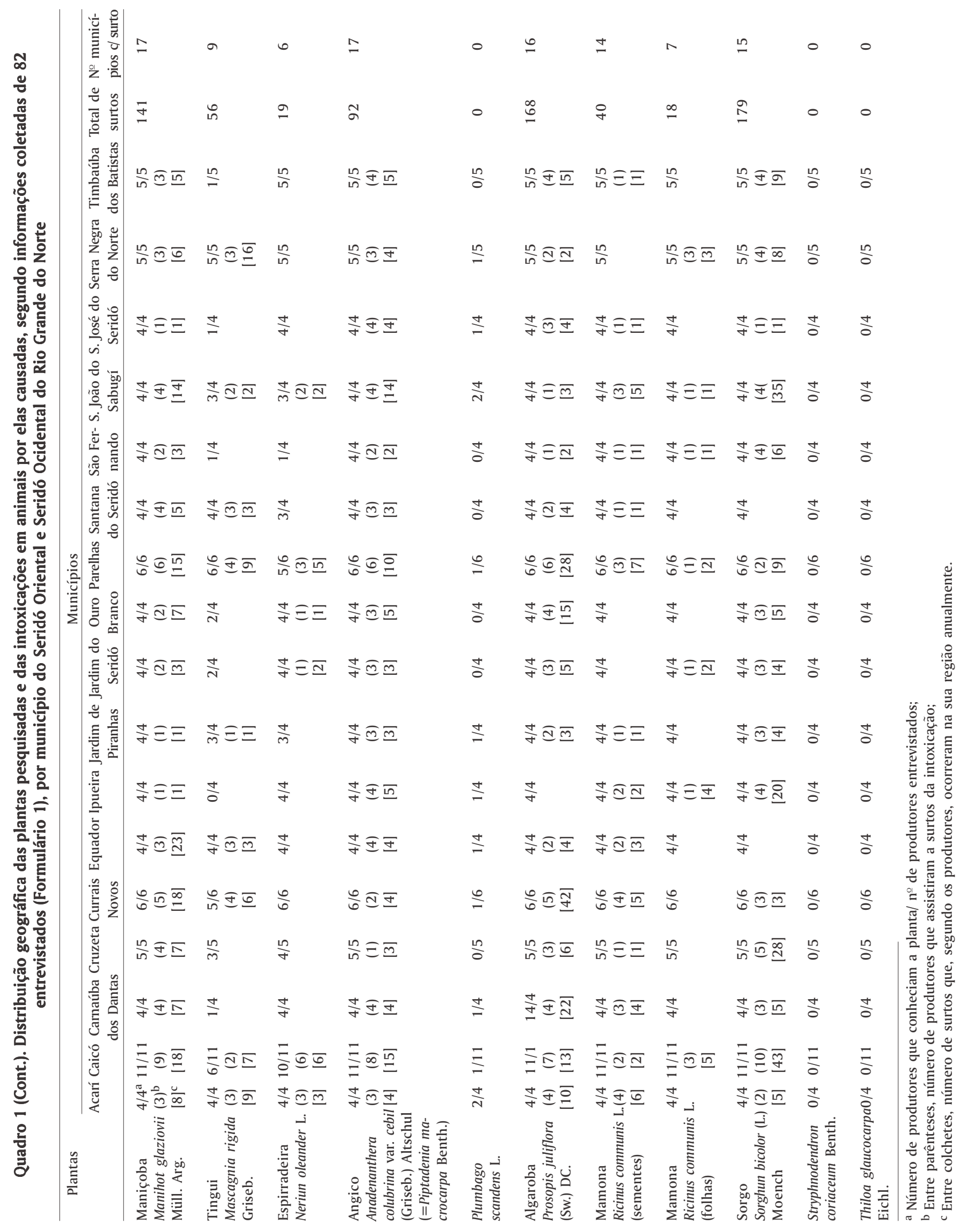


ram em aproximadamente 15 dias, sendo que um permaneceu em decúbito por 40 dias.

Ipomoea carnea (canudo). Um entrevistado relatou a intoxicação em uma cabra e seu cabrito, sendo que ambos se recuperaram.

Manihot glaziovii (maniçoba). Todos os entrevistados conheciam a planta como tóxica. Quinze mencionaram que a intoxicação ocorre no início das chuvas. Um relatou que dois bovinos foram encontrados mortos de um total de 30 existentes, em virtude disso a área foi isolada para evitar intoxicações. Outro relatou que, no início do período chuvoso, de 30 bovinos, adoeceram 5 e morreram 3, após um curso clínico de aproximadamente 30 minutos. Outro relatou que no início das chuvas, uma vaca foi encontrada morta entre 60 bovinos que pastavam em um cercado. Folhas de maniçoba foram encontradas no rúmen. Um entrevistado relatou que no início das chuvas, de 51 garrotes adoeceram 4 e morreram 2 , após um curso clínico rápido. As plantas tinham sido quebradas e havia sinais de que tinham sido ingeridas pelos animais. Na região, $M$. glaziovii é mais encontrada nas áreas mais altas, de serra.

Mascagnia rigida (tinguí). Vinte e cinco entrevistados conheciam a intoxicação em bovinos, sendo que 2 a relataram em jumentos. Um relatou que em agosto, no período do início da estiagem, de 500 bovinos colocados em uma área alta, de serra, 75 adoeceram, sendo que morreram 60 e 15 se recuperaram. Foi tentado arrancar a planta pela raiz com 10 trabalhadores, por 2 meses seguidos, más quando choveu brotou em quantidade aparentemente superior à existente anteriormente. Outro relatou que de 150 bovinos que no período de estiagem estavam sendo retirados de uma serra, 3 caiaram e morreram em aproximadamente 20 minutos. Um entrevistado relatou que de 100 bovinos que estavam sendo transportados, 2 caíram, mas se recuperaram espontaneamente, após terem sido deixados no caminho.

Nerium oleander (espirradeira). Um entrevistado relatou que em 2002, no período seco, material de plantas podadas num jardim foi colocado em uma área na que havia 8 vacas que o ingeriram, tendo adoecido todas e morrido 5. Outro relatou que, no mês de setembro, material dessa planta triturado junto com capins de um pátio de um colégio, foi fornecido a 40 bovinos de várias idades, que se encontravam presos num curral, tendo adoecido 28 e morrido 3 . Outro relatou que, num período de escassez de alimento, 3 bovinos ingeriram a planta que tinha sido cortada em um sítio vizinho e jogada por cima do muro; 2 bovinos morreram e 1 recuperou-se. Em outro surto, no período de estiagem, a planta foi cortada num cemitério e jogada no cercado vizinho onde 20 bovinos adoeceram e 7 morreram. Segundo os entrevistados, o período entre a ingestão da planta e a morte dos animais variou de 20 minutos a 5 dias.

Anadenanthera colubrina var. cebil (=Piptadenia macrocarpa) (angico). Sete entrevistados mencionaram que a intoxicação ocorre após a quebra e queda de galhos das árvores durante a ocorrência de chuvas ou ventanias. Três relataram que os bovinos se intoxicaram após o corte da planta para aproveitamento da madeira e outros 3 relataram que a intoxicação ocorreu após a brotação da planta. Um relatou casos em um rebanho de 200 ovinos dos quais 18 morreram após terem acesso a brotos da planta que tinham sido cortadas por formigas e estavam no chão.
O surto ocorreu após as primeiras chuvas e os sinais clínicos caracterizaram-se por dificuldade para movimentar-se, empanzinamento, andar cambaleante, pelo arrepiado, dificuldade respiratória e quedas. Todos os animais morreram em um período de, no máximo, duas horas; no rúmen foram encontradas numerosas folhas da planta. Diversos entrevistados relataram que têm cuidado quando vão cortar árvores de P. macrocarpa, retirando os animais do cercado ou queimando as folhas ou galhos cortados.

Plumbago scandens (louco). Treze entrevistados relataram a presença da planta, porém nenhum relatou casos de intoxicação.

Prosopis juliflora (algaroba). Um entrevistado relatou que no fim da estiagem, em um rebanho de 200 bovinos, 8 adoeceram e 4 morreram após um curso clínico de até um ano, os demais se recuperaram em outro pasto fora do baixio onde predominava a planta. Outro relatou que nas secas de 1993 e 1994 , de 120 bovinos e 50 ovinos, adoeceram 65 e morreram 60 bovinos, após curso clínico de até 3 meses; nos ovinos não foram observados sinais clínicos. Diversos entrevistados mencionaram que são observados casos esporádicos da doença em áreas de baixio onde a planta predomina. Casos menos freqüentes são observados em caprinos nessas mesmas áreas. Nenhum produtor mencionou a ocorrência da doença em ovinos.

Ricinus communis (mamona). Um entrevistado relatou a intoxicação em 15 bovinos, de um rebanho de 180, que apresentaram sinais nervosos 6 horas após terem sido colocadas, durante o período de seca, em uma área onde havia $R$. communis. Os bovinos foram retirados da área e os animais afetados se recuperaram espontaneamente. Seis relataram que administravam a planta no cocho, durante épocas de seca, em proporções crescentes até atingir quantidades que fossem ingeridas ad libitum entre o fim da tarde e a manhã seguinte. Como esses produtores acreditavam que o fator que desencadeava a intoxicação era a ingestão de água após o consumo da planta, os animais eram deixados por esse período sem beber água.

Sorghum bicolor (sorgo). Intoxicação por sorgos graníferos, utilizados para pastejo, ou por variedades forrageiras foram descritas por diversos entrevistados. Cinco relataram a ocorrência da intoxicação em bovinos que foram soltos em áreas onde o sorgo estava rebrotando após ter sido pastejado ou cortado. A maioria dos produtores menciona que os surtos ocorrem durante a seca, em áreas irrigadas ou em cultivos de vazante. Em todos os casos os animais apresentaram sinais clínicos agudos após terem sido soltos na área ou apareceram mortos no dia seguinte. A morbidade variou de 1,6 a 8\% e a letalidade foi de até $50 \%$, sem que em nenhum caso tivesse sido realizado o tratamento específico.

Nenhum dos entrevistados conhecia Thiloa glaucocarpa (sipaúba), Enterolobium gummiferum (orelha-de-onça) e Stryphnodendron coriaceum (barbatimão-do-nordeste); alguns entrevistados conheciam Lantana spp (chumbinho) e Ipomoea riedelii (anicão), mas não sabiam da toxicidade das mesmas.

Ocorrência e epidemiologia de intoxicações por plantas que não tinham sido descritas no Brasil antes deste levantamento (Formulários 2 e 3)

Os dados sobre intoxicações por três plantas, desconhecidas como tóxicas na literatura brasileira, que foram menciona- 


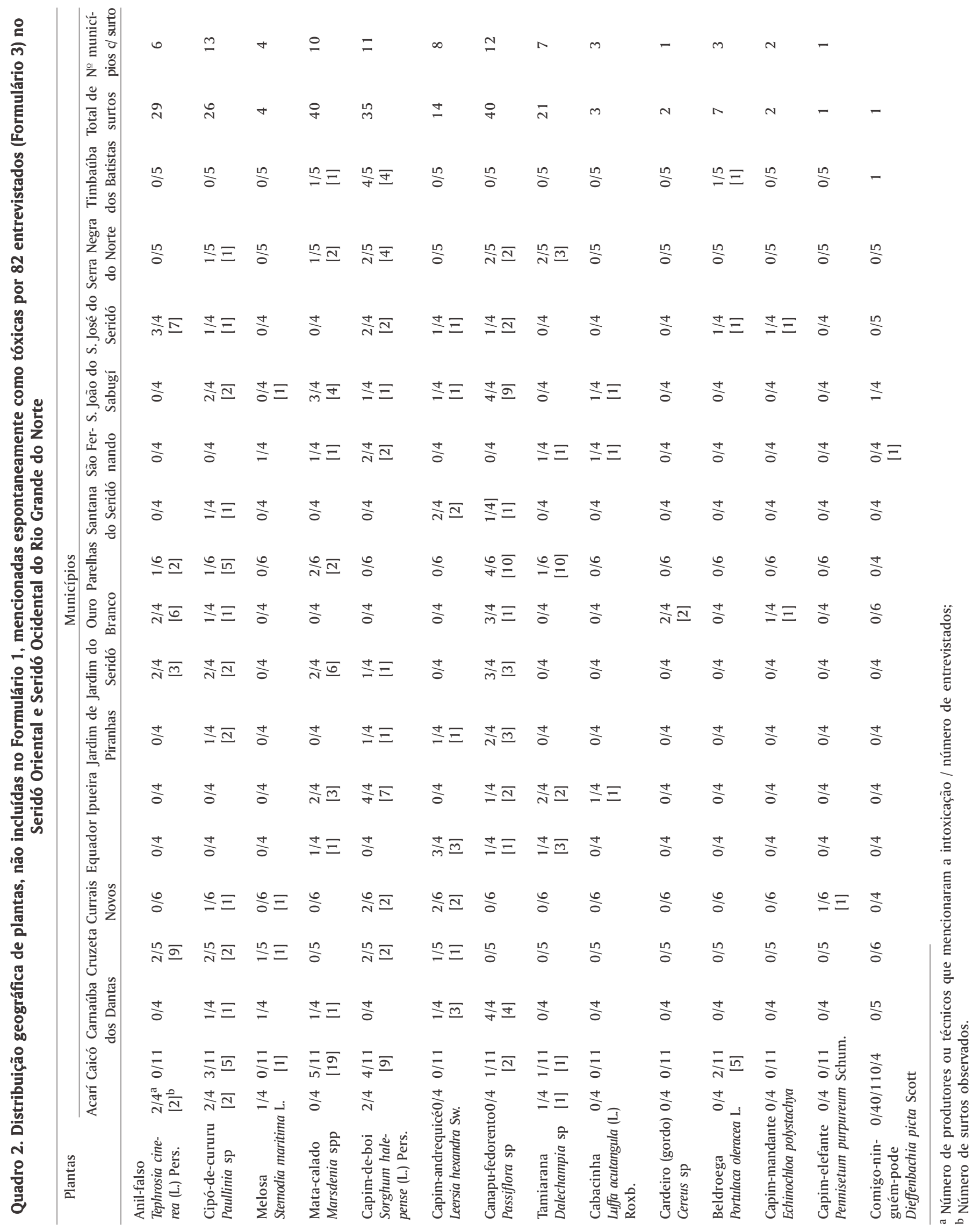


das pelos produtores no Formulário 2 (Quadro 2) e as respostas às perguntas do Formulário 3 sobre as intoxicações por estas plantas são apresentadas a seguir:

Marsdenia sp (mata-calado). Seis surtos desta intoxicação foram relatados pelos entrevistados. Um surto ocorreu no município de São José do Seridó em 17 bovinos que foram introduzidos numa área onde havia Marsdenia sp (Fig.2, 3 e 4), dos quais adoeceram 7 e morreu 1, após terem ingerido as folhas da planta. Trinta bovinos que estavam na mesma área não adoeceram. Os sinais clínicos caracterizaram-se por incoordenação, andar rígido, debilidade dos membros anteriores, decúbito esternal e, ocasionalmente, decúbito lateral. Os bovinos permaneciam se alimentando. Um animal morreu após 5 dias e os restantes recuperaram-se em 2-4 dias.

Um surto de intoxicação foi relatado em ovinos no município de Jardim do Seridó. Após as primeiras chuvas, no início de janeiro, morreram aproximadamente 270 ovinos de um total de 700. Muitos animais foram encontrados mortos, alguns apresentando incoordenação, tremores, salivação e decúbito, seguindo-se a morte em poucas horas. Poucos animais com sinais mais discretos se recuperaram. Não foram realizadas necropsias. A área estava invadida por mata-calado e, segundo os produtores, os ovinos tinham ingerido quantidades significativas das folhas do arbusto.

Outro entrevistado relatou um surto no período de estiagem, em um rebanho de 100 bovinos jovens dos quais adoece-

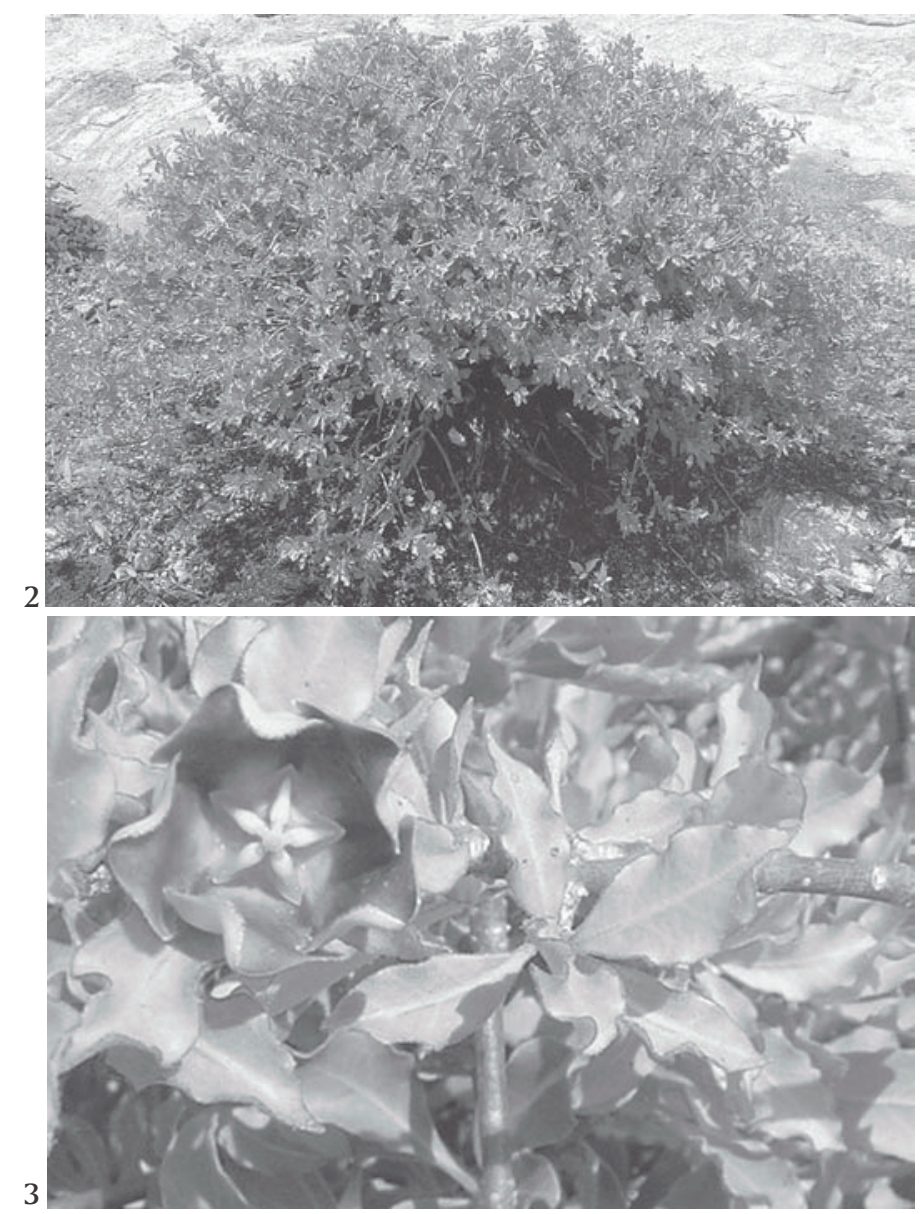

ram 15 e morreram 14, após apresentarem sinais neurológicos e permanecer 3-5 dias em decúbito. Esse produtor observou que os animais ingeriam as folhas e batatas da planta e, alguns, mesmo na época de chuva, continuavam a arrancar as batatas com as patas e chifres. Ele decidiu arrancar as batatas e colocou 5 batatas para 10 suínos gordos de aproximadamente $80 \mathrm{~kg}$. A redor de uma hora após o início da ingestão os suínos apresentaram salivação excessiva, vocalização, quedas e decúbito com movimentos de pedalagem. Cinco suínos morreram e os demais se recuperaram.

Outro entrevistado relatou que no período de estiagem, de 100 bovinos, 6 adoeceram e 2 morreram, após um curso clínico de 4 dias. Outro entrevistado colocou no mês de outubro 80 bovinos jovens em uma área onde tinha a planta; 12 adoeceram e 7 morreram em aproximadamente 3 dias. Esses dois entrevistados relataram que, após os surtos, alguns animais adquiriram o hábito de arrancar com as patas e os chifres as batatas da planta para alimentar-se.

Um entrevistado informou que no período de estiagem, em uma área que tinha 300 bovinos, 30 caprinos e 70 ovinos, adoeceram 20 bovinos e morreram 12, após um curso clínico de 38 dias. Um animal foi aberto e a planta foi encontrada no tubo digestivo. A intoxicação por esta espécie de Marsdenia foi reproduzida experimentalmente em ovinos e caprinos (RietCorrea et al. 2004).

Fig.2. Marsdenia sp. Município de Caicó, Rio Grande do Norte.

Fig.3. Inflorescência de Marsdenia sp. Município de Caicó, Rio Grande do Norte.

Fig.4. Cápsula de Marsdenia sp. Município de Caicó, Rio Grande do Norte.

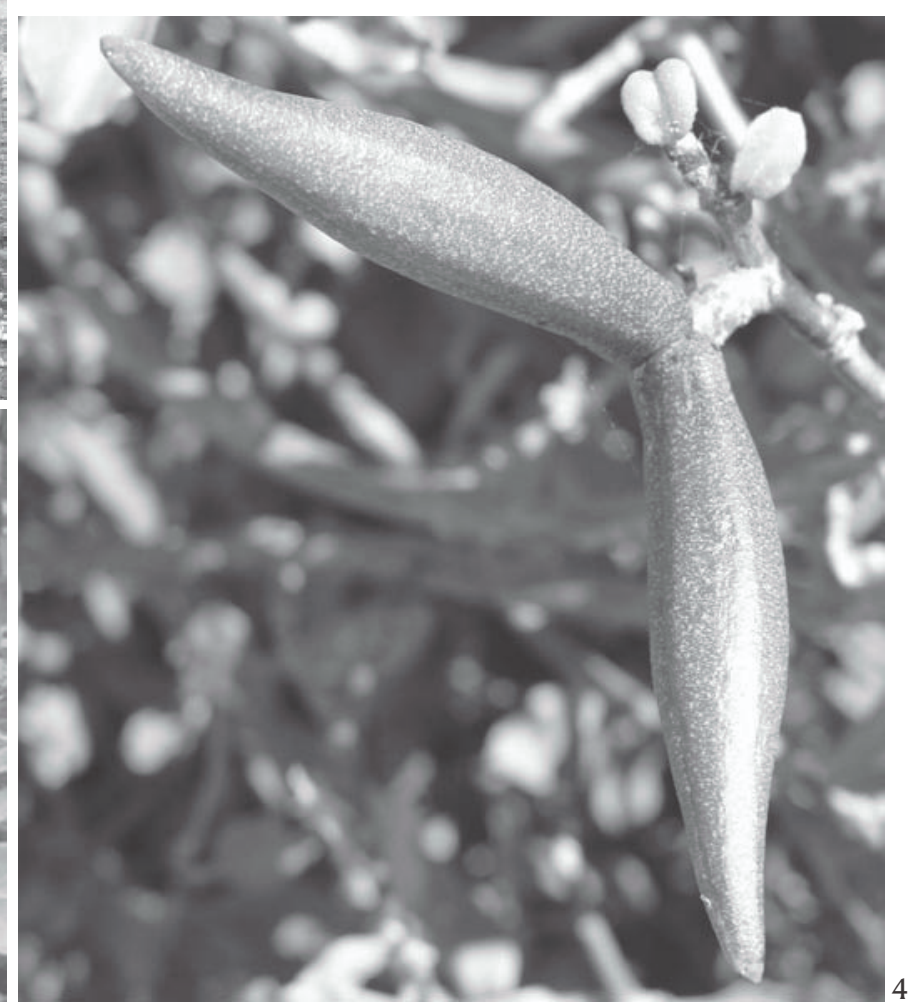


Sorghum halepense (capim-de-boi). Vinte e cinco entrevistados mencionaram o capim-de-boi como planta tóxica para bovinos. A intoxicação ocorre no início das chuvas ou em período de estiagem em áreas irrigadas. A planta, mediante o teste do papel picrossódico, foi demonstrada conter ácido cianídrico. Esta espécie é encontrada às margens de açudes, invadindo plantações de outros capins, como Pennisetum purpureum, Echinochloa polystachya e Leersia hexandra, ou em áreas irrigadas onde invadem culturas de sorgo, milho, tomate e outras. A intoxicação ocorre quando $S$. halepense está na fase inicial de crescimento ou rebrotando. Todos os entrevistados relataram o rápido início da doença imediatamente após a colocação dos animais na pastagem com a planta. Em alguns casos os animais se recuperaram espontaneamente após serem retirados do local. A morbidade mencionada por 4 entrevistados foi de até $30 \%$ e a letalidade variou de 0 a $100 \%$.

Tephrosia cinerea (anil-falso). Doze entrevistados observaram surtos de intoxicação por Tephrosia cinerea (Fig.5 e 6). Um relatou que em 2000, no final do período de estiagem, num rebanho de 60 ovinos, 6 animais adoeceram (marrãs e ovelhas) e 3 marrãs morreram. Na área a planta representava aproximada-

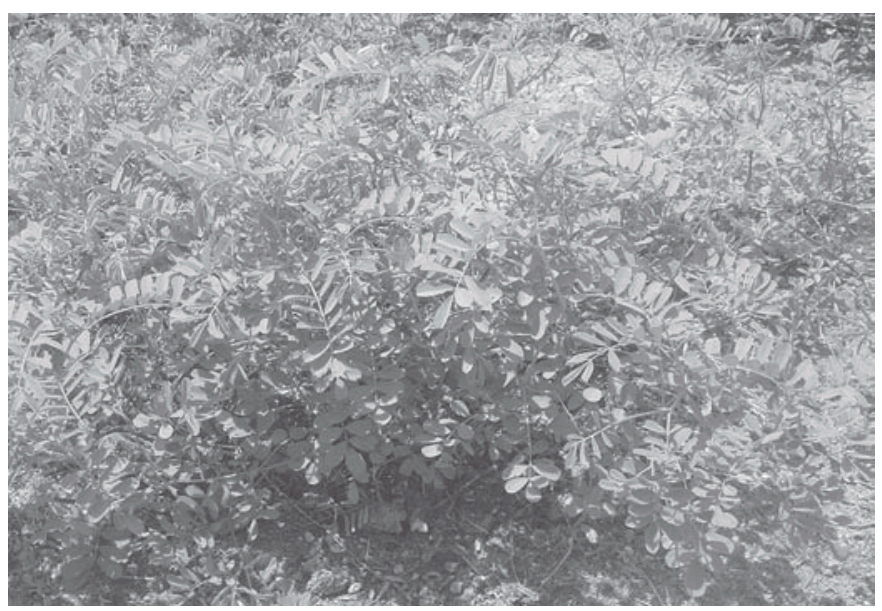

Fig.5. Tephrosia cinerea. Município de São José do Seridó, Rio Grande do Norte.

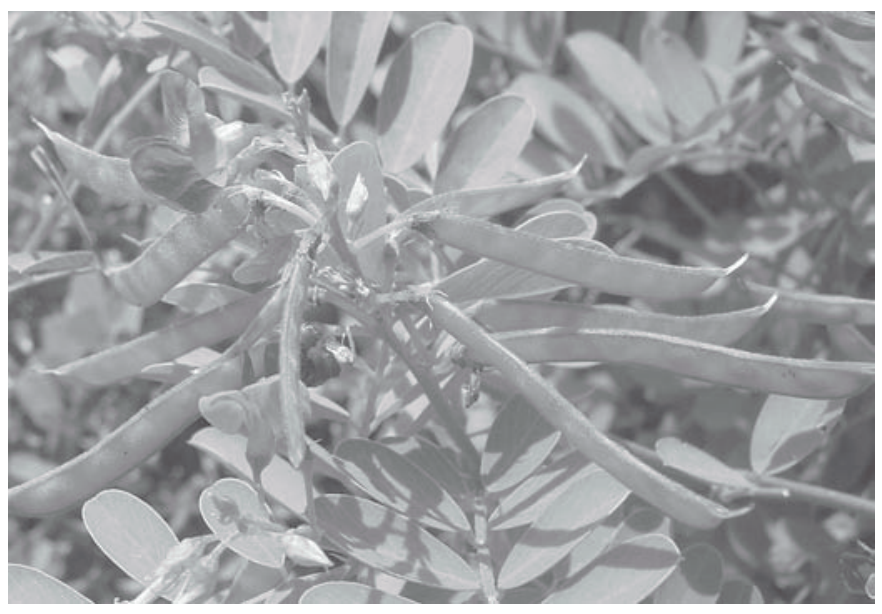

Fig.6. Inflorescência e vagens de Tephrosia cinerea. Município de São José do Seridó, Rio Grande do Norte. mente $80 \%$ da vegetação. Após o final da seca as ovelhas que estavam afetadas se recuperaram. Outro entrevistado relatou a ocorrência da doença no fim do período seco, em uma pequena área onde a planta representava aproximadamente $80 \%$ da vegetação. De um total de 40 ovinos e 8 bovinos, adoeceram 30 ovinos de várias idades e todos morreram após um curso clínico de aproximadamente 30 dias. Em outra fazenda, no período de estiagem, onde a planta representava aproximadamente $90 \%$ da vegetação e havia 30 bovinos e 40 ovinos, adoeceram e morreram 16 ovinos. Um outro entrevistado relatou que de 100 ovelhas, 30 apresentaram sinais clínicos. Três semanas após o início da doença os ovinos foram retirados para outra fazenda, contudo, morreram 4 , mas os demais se recuperaram. A planta parece pouco palatável e somente ovinos, em áreas onde ela é dominante, a ingerem. Caprinos e bovinos não são afetados e aparentemente não ingerem a planta. A intoxicação é de curso crônico e o principal sinal clínico e ascite, o que faz que os produtores a conheçam como barriga d'água. A maioria dos animais morre após um curso clínico de algumas semanas ou meses. Alguns se recuperam se forem retirados das pastagens ou após as primeiras chuvas. Em um animal necropsiado foi observada grande quantidade de líquido na cavidade abdominal, torácica e pericárdica. $O$ fígado apresentava superfície muito irregular, esbranquiçada, com numerosos nódulos de menos de $1 \mathrm{~mm}$ na superfície. Histologicamente o fígado apresentava, linfáticos dilatados, fibrose periportal e subcapsular, e proliferação de células dos ductos biliares. A doença foi reproduzida experimentalmente em ovinos (Santos 2006).

Outras plantas mencionadas como tóxicas pelos produtores da região, mas cuja toxicidade não está comprovada (Formulários 2 e 3)

Dados sobre algumas plantas tóxicas ou supostamente tóxicas mencionadas pelos entrevistados nos Formulários 2 e 3 (Quadro 2) são apresentados a seguir:

Paullinia sp (cipó-de-cururu). Dezenove entrevistados mencionaram a toxicidade desta planta como causa de problemas digestivos e nervosos quando é administrada junto com outras plantas, já que a planta não é ingerida espontaneamente. Um relatou que em janeiro, no início das chuvas, foi dada a planta misturada com capim a 100 bovinos, 4 dos quais se intoxicaram e 1 morreu. Caiam para trás, davam coices e cambaleavam. 0 que morreu teve um curso clínico de aproximadamente 14 horas.

Stemodia maritima (melosa). Seis entrevistados relataram a toxicidade desta planta, que ocorre em áreas salinizadas, como causa de abortos e empanzinamento.

Leersia hexandra (capim-andrequicé). Três entrevistados relataram a toxicidade desta planta como causa de mortes após um curso agudo. Um relatou que durante a estiagem cortaram e colocaram $L$. hexandra em cochos do curral, para 20 bovinos. No dia seguinte foram encontrados 6 mortos. Outro relatou que no período de estiagem, de 200 bovinos adoeceram 8 . Todos se recuperaram em 12 horas. A planta era cortada e espalhada em pequenos montes que antes de serem ingeridos passaram aproximadamente 3 horas numa área úmida. Os animais apresentaram empanzinamento, andar cambaleante, quedas e dificuldade 
respiratória. Outro relatou que de 120 bovinos, 23 adoeceram e morreram em aproximadamente 15 minutos, após comerem o capim cortado na beira de um açude. Segundo o produtor ficavam tristes, davam coices e caiam com movimentos de pedalagem. Em outra fazenda, de um total de 20 bovinos, 3 adoeceram e morreram aproximadamente 2 horas após terem sido colocados na beira de uma barragem onde havia o capim.

Passiflora sp (canapú-fedorento). Treze entrevistados mencionaram esta planta como causa de aborto em bovinos, $6 \mathrm{em}$ equiinos, 3 em caprinos e 2 em ovinos.

Dalechampia sp (tamiarana). Nove entrevistados mencionaram esta planta como causadora de lesões irritativas na mucosa oral em caprinos, bovinos e ovinos.

Luffa acutangula (cabacinha). Esta planta foi mencionada por três entrevistados como causa de abortos em bovinos e ovinos. Um colocou o fruto da planta em água e administrou a bezerros como anti-helmíntico, ocasionando a morte de 20 animais.

Cereus sp (cardeiro). Dois entrevistados mencionaram a intoxicação por "cardeiro-gordo" que é como designam esta planta após as primeiras chuvas, quando fica com bastante água e ao corte de facão apresenta aspecto avermelhado. Em um caso, a planta foi queimada para eliminar os acúleos, triturado na forrageira e dada misturada a farelo de trigo a 14 vacas. Todos os animais adoeceram e 2 morreram. Os sinais caracterizaramse por incoordenação dos membros posteriores e timpanismo. Foram tratados mediante punção do flanco lateral esquerdo e administração de ruminol e antitóxico.

Portulaca oleracea (beldroega). Quatro entrevistados observaram quadros digestivos com timpanismo em bovinos ingerindo esta planta.

\section{Outras plantas tóxicas mencionadas pelos produtores que não foram incluídas no Formulário 1. \\ Echinochloa polystachya (capim-mandante) e Pennisetum} purpureum (capim-elefante). Dois entrevistados relataram surtos de intoxicação por E. polystachya e um por $P$. purpureum em bovinos. Os animais, que foram alimentados com capim em brotação, após a ocorrência das primeiras chuvas, apresentaram uma doença aguda com morte em no máximo 30 minutos.

Dieffenbachia picta (comigo-ninguém-pode). A intoxicação por esta planta foi observada por um entrevistado no período de estiagem. As folhas da planta tinham sido cortadas e colocadas num lugar onde passavam os animais. De um rebanho de 50 bovinos, 50 caprinos e 30 ovinos, adoeceram 3 bovinos (um touro, uma vaca e uma novilha) e uma cabra adulta. $\mathrm{O}$ touro e a vaca morreram rapidamente. A novilha apresentou salivação, cólicas e diarréia hemorrágica, morrendo 15 dias após. A cabra recuperou-se após apresentar língua inchada e para fora da cavidade oral e salivação, por aproximadamente 15 dias.

\section{DISCUSSÃO}

A informação gerada por este trabalho, mesmo com as limitações inerentes às entrevistas, principalmente pelas dificuldades de comprovar alguns dos fatos mencionados pelos entrevistados, permitiu obter dados importantes em relação à ocorrência, epidemiologia e importância das intoxicações por plantas na região estudada. Isso é demonstrado por que, além de ter-se obtido informação sobre as plantas tóxicas da região, indicou a ocorrência de três intoxicações que não tinham sido descritas anteriormente no Brasil.

Conforme os Quadros 1 e 2 que são o resumo dos resultados obtidos pela aplicação dos Formulários 1 e 2 , respectivamente, e pelos resultados das entrevistas do Formulário 3, é evidente que as intoxicações por Ipomoea asarifolia e Aspidosperma pyrifolium são as mais freqüientes. Como foi relatado anteriormente (Medeiros et al. 2003a, Riet-Correa et al. 2006a), I. asarifolia afeta caprinos, ovinos e bovinos, na época de estiagem quando os animais não têm disponibilidade de forragem, sendo os ovinos a espécie mais afetada. A alta frequiência da doença em bovinos, mencionada nas entrevistas, evidencia a importância da intoxicação também nesta espécie na região. No entanto, devemos considerar que na área estudada a população de 140.567 bovinos é maior que a de 67.363 ovinos e 16.525 caprinos (IBGE 2002b).

Em relação aos abortos associados à ingestão de Aspidosperma pyrifolium, diversos entrevistados mencionam a sua ocorrência em ovinos e bovinos. Até o momento os abortos por $A$. pyrifolium foram comprovados somente em caprinos (Medeiros et al. 2004). Surtos espontâneos de abortos em ovinos e bovinos deverão ser estudados para comprovar a participação de $A$. pyrifolium como causa dos mesmos. Como mencionado pelos entrevistados, os abortos ocorrem, principalmente, após o final da época de chuvas, quando há pouca disponibilidade de forragem. Nessa época A. pyrifolium ainda esta verde e suas folhas estão entre as últimas a cair. Foi mencionada, também, pelos entrvistados, a ocorrência de quadros nervosos em bovinos, muares e eqüinos associados à ingestão de $A$. pyrifolium. O efeito tóxico de outra espécie de Aspidosperma, A. pyricollum, foi demonstrado em trabalhos experimentais realizados em bovinos para determinar a causa de uma doença conhecida como popa-inchada (Döbereiner \& Tokarnia 1982), que posteriormente foi comprovado que era causada pela ingestão de Thiloa glaucocarpa (Tokarnia et al. 1981). Na intoxicação experimental realizada por Döbereiner \& Tokarnia (1982), os animais que ingeriram $A$. pyricollum apresentaram sinais clínicos muito semelhantes aos descritos pelos produtores durante as entrevistas, sugerindo que $A$. pyrifolium, além dos abortos, causa espontaneamente um quadro nervoso, tanto em bovinos quanto em muares e eqüinos.

Outro tipo de intoxicação importante na região é a causada por plantas cianogênicas, incluindo Manihot glaziovii, Anadenanthera colubrina var. cebil, Sorghum bicolor e Sorghum halepense. A informação dos entrevistados referente às intoxicações por $M$. glaziovii e $A$. colubrina é semelhante à descrita anteriormente (Tokarnia et al. 2000). A primeira ocorre principalmente no início das chuvas e a segunda quando árvores ou ramas da árvore são cortadas ou quebram-se por efeito do vento ou chuva. Por outro lado, foi constatado que o conhecimento da toxicidade destas plantas por parte dos produtores faz com que eles apliquem medidas preventivas para evitar as intoxicações. Tanto $S$. bicolor quanto $S$. halepense são aparentemente causa freqüente de intoxicação cianídrica na região, principalmente no início das chuvas quando estas plantas estão em brotação, ou em áreas irrigadas. Um surto de intoxicação por S. halepense foi 
descrito, recentemente, em bovinos na Paraíba (Nóbrega et al. 2006).

Uma intoxicação freqüente em bovinos foi a causada por favas de algaroba, Prosopis juliflora, principalmente em áreas de baixio onde a planta é invasora e as favas se tornam forragem preferencial nos meses de setembro-dezembro. Esta situação difere da observada antes do conhecimento da toxicidade da planta, na década de 1980 . A frequiência da doença diminuiu significativamente, já que produtores que utilizam favas de algaroba como concentrado as administram aos bovinos em quantidades menores do que $30 \%$ da ração e por períodos curtos, de no máximo 3-4 meses. Alguns produtores mencionaram, também, a intoxicação em caprinos, que por serem mais resistentes que os bovinos, apresentam menor frequiência da doença. Surtos de intoxicação em caprinos foram descritos recentemente na Paraíba (Lima et al. 2004). Nenhum entrevistado mencionou a intoxicação em ovinos, o que confirma a resistência desta espécie, que pode ingerir rações contendo 60-100\% de vagens de algaroba, durante um ano, sem ser afetada (Lima et al. 2004).

Diversos entrevistados mencionaram a intoxicação por Crotalaria retusa em eqüinos, bovinos e ovinos, sendo as informações semelhantes às publicadas recentemente (Nobre et al. 2004a,b, 2005). No entanto, um produtor mencionou a intoxicação em emas, numa área invadida pela planta, tendo encontrado sementes em grande quantidade no inglúvio.

Quatro surtos de intoxicação por Nerium oleander foram relatados pelos entrevistados. Esta é uma intoxicação freqüente-mente mencionada em outros países que é aparentemente rara no Brasil, apesar da grande difusão da planta como ornamental. Em todos os surtos mencionados houve um fator epidemiológico em comum: a administração acidental da planta após ter sido cortada, misturada ou não com outras pastagens. Casos de intoxicação por $N$. oleander tinham sido descritos anteriormente no Rio Grande do Norte em bovinos que tiveram acesso a plantas cortadas e colocadas acidentalmente à disposição dos bovinos; há informação de um surto em Mossoró, onde morreram 4 bovinos que ingeriram a planta que tinha sido cortada e jogada por cima de um muro (Costa \& Vasconcelos 1989) e de outro surto em São José do Sabugí, onde morreram 5 bovinos que ingeriram a planta que tinha sido cortada numa praça da cidade (Nóbrega 2005). Em conseqüência desses relatos é evidente que $N$. oleander deve ser considerada como planta tóxica de alguma importância no Rio Grande do Norte e em outros estados do semi-árido, já que é bastante difundida como planta ornamental.

Outra planta tóxica mencionada pelos entrevistados foi Mascagnia rigida. Segundo Tokarnia et al. (2000), M. rigida é a principal planta tóxica do Nordeste, no entanto, por ser bem conhecida pelos produtores, a intoxicação raramente é motivo de consulta aos veterinários. Um fato que chama a atenção é o relato, por dois produtores, da ocorrência da intoxicação por $M$. rigida em jumentos, o que precisa ser confirmado. Outras plantas tóxicas mencionadas pelos entrevistados, aparentemente de menor importância na região, foram Brachiaria decumbens como causa de fotossensibilização, Enterolobium contortisiliquum como causa de diarréia e ocasionalmente fotossensibilização e aborto, Indigofera suffruticosa como causa de hemoglobinúria e Ipomoea carnea como causa de sinais nervosos.

Plumbago scandens foi recentemente descrita na Paraíba como planta tóxica para caprinos (Medeiros et al. 2001). No entanto, na área pesquisada neste trabalho, somente 13 produtores conheciam a planta e nenhum tinha conhecimento de que a mesma fosse tóxica. Esse fato sugere que P. scandens é uma planta tóxica de pouca importância, pelo menos na região estudada.

Apesar de todos os entrevistados conhecerem Ricinus communis, somente um relatou um surto de intoxicação em animais que, numa época de carência de forragem, foram soltos numa área invadida pela planta. A toxicidade das folhas de R. communis é experimentalmente bem conhecida (Tokarnia et al. 2000), mas não há relatos na literatura brasileira que comprovem a ocorrência de intoxicação espontânea. Históricos sobre a intoxicação natural em bovinos provêm, sobretudo, da região Nordeste em áreas de solos férteis invadidas pela planta ou cultivadas (Tokarnia et al. 2000). Chama a atenção o relato de diversos produtores que empregavam folhas de $R$. communis em quantidades crescentes até atingir quantidades consideráveis, ingeridas ad libitum entre o fim da tarde e a manhã seguinte, como único volumoso, o que sugere que os animais apresentam um mecanismo de adaptação ao princípio tóxico contido nas folhas, o alcalóide conhecido como ricinina. Segundo Tokarnia et al. (2000), a dose letal de folhas da planta é de $20 \mathrm{~g} / \mathrm{kg}$ e não há variações entre plantas das regiões Nordeste e Sudeste; a ingestão da planta não confere imunidade, mas há evidências de que induz pequena tolerância quando há ingestões repetidas.

Plantas tóxicas de importância em outras regiões do Nordeste, incluídas no Formulário 1, como Thiloa glaucocarpa, Stryphnodendron coriaceum e Enterolobium gummiferum não são conhecidas pelos entrevistados e certamente não ocorrem na região. Lantana spp e Ipomoea riedelii são plantas pouco conhecidas, que provavelmente não causam intoxicação nas condições da região.

Nas informações obtidas com o Formulário 2, surgiram diversas plantas que os entrevistados relataram como tóxicas sem que tenham sido perguntados sobre as mesmas. Dessas, as mais importantes foram Sorghum halepense, já mencionado anteriormente, Marsdenia sp e Tephrosia cinerea. Estas duas últimas, cuja toxicidade não tinha sido descrita anteriormente a este levantamento, são sem dúvida plantas tóxicas de importância, não só na região estudada, mas também em outras regiões do semi-árido. No semi-árido há pelo menos três espécies de Marsdenia que causam intoxicação, mas nenhuma dessas foi identificada botanicamente com precisão. Duas espécies são ramas (trepadeiras) e a outra é arbustiva, com até $1 \mathrm{~m}$ de altura. Esta última (Fig.2, 3 e 4) é a mencionada pelos produtores como tóxica na região estudada. Tanto as folhas como as batatas destas plantas causam sinais nervosos em ovinos, caprinos e bovinos, caracterizadas por tremores musculares, salivação, movimentos de mastigação, incoordenação, perda de equilíbrio e decúbito, primeiro esternoabdominal e depois lateral, mas não ocorrem lesões histológicas (Riet-Correa et al. 2004, 2006a). A intoxicação ocorre quando os animais ingerem as folhas, principalmente em épocas de estiagem ou quando são introduzidos nas áreas invadidas pela planta, ou quando acidentalmente as raízes são expostas e os ani- 
mais as ingerem espontaneamente. Um dado importante na epidemiologia da doença é o fato mencionado pelos entrevistados que alguns animais aprendem a desenterrar as raízes da planta, principalmente da espécie arbustiva que causou os surtos mencionados no Rio Grande do Norte, que apresenta raízes superficiais em terrenos arenosos. É importante registrar que a letalidade, dependendo da dose ingerida, é variável. Em trabalhos experimentais, as 3 espécies de Marsdenia testadas foram tóxicas, e com doses de $10 \mathrm{~g}$ de raízes ou $20 \mathrm{~g}$ de folhas por $\mathrm{kg}$ de peso os animais recuperam-se (Riet-Correa et al. 2004). Ainda as raízes e os frutos destas plantas são utilizados como veneno para matar ratos, cachorros e outros animais. A intoxicação em suínos que ingeriram raízes da planta, administradas por um produtor para confirmar a toxicidade das mesmas, comprova a susceptibilidade desta espécie à intoxicação.

Outra planta importante é Tephrosia cinerea, espécie invasora que intoxica ovinos que a ingerem na época de seca, onde esta planta torna-se dominante, em consequiência da agricultura intensiva em áreas que são cultivadas todos os anos, com diversos cultivos (feijão, mandioca, milho). Segundo dois produtores, outro fator que favorece a disseminação da planta e o pastejo com lotações muito altas de bovinos. A planta é pouco palatável, mas quando não há outras forrageiras disponíveis os ovinos a ingerem. T. cinerea é hepatotóxica causando um quadro característico, de ascite crônica, conhecido como barriga d'água. Os animais afetados podem apresentar sinais clínicos algumas semanas ou meses antes de morrerem, embora possam se recuperar se forem retirados das pastagens. Macroscopicamente, além da ascite observa-se consistência aumentada e superfície irregular do fígado. Histologicamente as principais lesões do fígado são a fibrose periportal e subcapsular. Como forma de controle, os ovinos devem ser retirados das áreas invadidas pela planta. A única forma de evitar a intoxicação é eliminando a planta ou não colocando ovinos em áreas onde ela ocorre em grandes quantidades. Em áreas de agricultura é importante detectar a presença da planta precocemente e elimina-la manualmente ou com herbicidas antes que haja a invasão da área, visto que, ocorrendo a planta como vegetação dominante, é muito difícil erradicála ou mesmo controlá-la. A doença foi reproduzida experimentalmente mediante a administração da planta a um ovino que ingeriu a mesma por 232 dias (Santos 2006).

Os produtores mencionaram, também, diversas plantas cuja toxicidade, em forma espontânea, não é comprovada. Algumas dessas como Paullinia sp, Passiflora sp, Dalechampia sp e Portulaca oleracea foram testadas experimentalmente sem causarem sinais clínicos (Tokarnia et al. 2000). Dentre essas, Portulaca oleracea é descrita como causando intoxicação por oxalatos em outros países (Radostits et al. 2000).

Três plantas que foram mencionadas pelos entrevistados, $L u f f a$ acutangula, Cereus sp e Stemodia maritima, não têm sido descritas como tóxicas, nem há experimentos que comprovem sua toxicidade. $\mathrm{O}$ estudo de surtos associados à ingestão destas plantas e a reprodução experimental das mesmas poderão comprovar sua toxicidade.

Algumas gramíneas, incluindo Echinochloa polystachya (capimmandante), Pennisetum purpureum (capim-elefante) e Leersia hexandra (capim-andrequicé), foram mencionadas por alguns entrevistados como causa ocasional de intoxicações. As duas primeiras podem causar intoxicação por nitratos e nitritos, principalmente após as primeiras chuvas depois de períodos de estiagem (Medeiros et al. 2003b). Conforme os históricos mencionados pelos entrevistados, é possível que Leersia hexandra cause, também, intoxicação por nitratos e nitritos.

Um entrevistado descreveu um surto de doença associada à ingestão de Dieffenbachia picta (comigo-ninguém-pode) que tinha sido cortada e colocada ao alcance dos animais que a ingeriram. Esta planta, que contém oxalatos que causam irritação na boca e língua, é bem conhecida como planta tóxica para animais de estimação e crianças (Loretti et al. 2003). A intoxicação foi reproduzida experimentalmente em ovinos (Armién \& Tokarnia 1994) e bovinos (Tokarnia et al. 1996). Alguns dos sinais clínicos mencionados pelo produtor, salivação e edema da língua, são característicos da intoxicação.

Mimosa tenuiflora é uma planta tóxica importante na região, como causa de malformações em ruminantes (Riet-Correa et al. 2006a,b), que não foi incluída no Formulário 1 por que na época do levantamento ainda não se tinha esta informação. Apesar da ocorrência de malformações na região estudada, nenhum produtor mencionou no Formulário 2 qualquer planta como causa dessas malformações. Isto por que, em geral, os produtores consideram que as malformações são problemas hereditários ou causadas por anti-helmínticos.

Agradecimentos.- Este projeto foi financiado pela Fundação de Amparo à Pesquisa da Paraíba/ Ministério de Ciência e Tecnologia, Edital 004/03 FAPESQ-MST, e pelo programa Institutos do Milênio (CNPq Proc. 420012/ 2005-2).

\section{REFERÊNCIAS}

Armién A.G. \& Tokarnia C.H. 1994. Experimentos sobre a toxidez de algumas plantas ornamentais em bovinos. Pesq. Vet. Bras. 14:69-73.

Costa E.S. \& Vasconcelos S.H.L. 1989. Algumas considerações sobre a toxicidade da "espirradeira" (Nerium oleander L.). Coleção Mossoroense, Escola Superior de Agricultura de Mossoró, RN, Série B, no.645, p.1-6.

Döbereiner J. \& Tokarnia C.H. 1982. Intoxicação experimental por Aspidosperma pyricollum em bovinos. Pesq. Vet. Bras. 2:31-36.

Duque J.G. 1964. O Nordeste e as lavouras xerófilas. Banco do Nordeste do Brasil, Fortaleza.

IDEMA 2002. Anuário Estatístico, Instituto de Desenvolvimento Econômico e Meio Ambiente do Rio Grande do Norte, Natal, 29:53-55, 206209.

Lima E., Riet-Correa F., Amorin S.L., Sucupira Júnior G. 2004. Intoxicação por favas de Prosopis juliflora (algaroba) em caprinos no nordeste do Brasil. Pesq. Vet. Bras. 24(Supl.):36-37.

Loretti A.P., Ilha M.R. \& Ribeiro R.E.S. 2003. Accidental fatal poisoning of a dog by Dieffenbachia picta. Vet. Hum. Toxicol. 45:233-239.

Medeiros R.M.T., Barbosa R.C., Lima E.F., Simões S.V.D. \& Riet-Correa F. 2001. Intoxication by Plumbago scandens in goats in Paraíba, northeastern Brazil. Vet. Hum. Toxicol. 43(3):167-169.

Medeiros R.M.T., Barbosa R.C., Riet-Correa, F., Lima E.F., Tabosa I.M., Barros S.S., Gardner D.R. \& Molyneux R.J. 2003a. Tremorgenic syndrome in goats caused by Ipomoea asarifolia in northeastern Brazil. Toxicon 41:933-935.

Medeiros R.M.T., Riet-Correa F., Tabosa I.M., Silva Z.A., Barbosa R.C., Marques A.V.M.S. \& Nogueira F.R.B. 2003b. Intoxicação por nitratos e nitritos em bovinos por ingestão de Echinochloa polystachya (capim-mandante) e Pennisetum purpureum (capim-elefante) no sertão da Paraíba. Pesq. Vet. Bras. 23:17-20. 
Medeiros R.M.T., Neto S.A.G., Riet-Correa F., Schild A.L. \& Sousa, N.L. 2004. Mortalidade embrionária e abortos em caprinos causados por Aspidosperma pyrifolium. Pesq. Vet. Bras. 24(Supl.):42.

Nobre V.M.T., Riet-Correa F., Dantas A.F.M., Tabosa I.M., Medeiros R.M.T. \& Barbosa Filho J.M. 2004a. Intoxication by Crotalaria retusa in ruminants and equiidae in the state of Paraíba, northeaster Brazil, p.275-279. In: Acamovich T., Stewart C.S. \& Pennycott T.W. (ed.) Plant Poisoning and Related Toxins. CAB International, Glasgow.

Nobre V.M.T., Riet-Correa F., Barbosa Filho J.M., Tabosa I.M. \& Vasconcelos J.S. 2004b. Intoxicação por Crotalaria retusa (Fabaceae) em equíídeos no semiárido da Paraíba. Pesq. Vet. Bras. 24:132-143.

Nobre V.M.T., Dantas A.F.M., Riet-Correa F., Barbosa Filho J.M., Tabosa, I.M. \& Vasconcelos J.S.V. 2005. Acute intoxication by Crotalaria retusa in sheep. Toxicon 45:347-352.

Nóbrega J.E. 2005. Comunicação pessoal (Centro de Saúde e Tecnologia Rural, UFCG, Campus de Patos, 58700-000 Patos, Paraíba).

Nóbrega J.E., Riet-Correa F., Medeiros R.M.T. \& Dantas A.F.M. 2006. Intoxicação por Sorhgum halepense (Poaceae) em Bovinos no semi-árido. Pesq. Vet. Bras. 26(4):201-204.

Radostits O.M., Gay C.C., Blood D.C. \& Hinchcliff K.W. 2000. Clínica Veterinária: um tratado de doenças de bovinos, ovinos, caprinos, suínos e equiídeos. 9a ed. W.B. Saunders, London, p.1631-1636.
Riet-Correa F., Silva D.M., Oliveira O.F., Simões S.V.D., Medeiros R.M.T. \& Nóbrega R.S. 2004. Intoxicação por Marsdenia spp (mata-calado) em ruminantes. Pesq. Vet. Bras. 24 (Supl.):50-51.

Riet-Correa F., Medeiros R.M.T. \& Dantas A.F. 2006a. Plantas tóxicas da Paraíba. SEBRAE, João Pessoa. 54p.

Riet-Correa F., Medeiros R.M.T., Tokarnia C.H. \& Döbereiner J. 2006b Toxic plants for livestock in Brazil: toxic species, economic impact and public health. Proc. 8th Int. Symposium on Poisonous Plants, Logan, Utah. (In press)

Santos J.C.A. 2006. Intoxicação em ovinos por Tephrosia cinerea. Tese de Mestrado, Curso de Medicina Veterinária de Pequenos Ruminantes, Universidade Federal de Campina Grande, Paraíba. (Dados ainda não publicados)

Tokarnia C.H., Armién A.G., Peixoto P.V., Barbosa J.D., Brito M.F. \& Döbereiner J. 1996. Estudo experimental sobre a toxidez de algumas plantas ornamentais em bovinos Pesq. Vet. Bras. 16:5-20.

Tokarnia C.H., Döbereiner J. \& Peixoto P.V. 2000. Plantas Tóxicas do Brasil. Editora Helianthus, Rio de Janeiro. 310p.

Tokarnia C.H., Döbereiner J., Canella C.F.C., Couceiro J.E.M., Silva A.C.C. \& Araújo F.V. 1981. Intoxicação de bovinos por Thiloa glaucocarpa (Combretaceae), no Nordeste do Brasil. Pesq. Vet. Bras. 1:111-132. 